\title{
1 CellDepot: A unified repository for scRNA-seq data and visual exploration
}

2 Authors: Dongdong Lin ${ }^{1 \dagger}$, Yirui Chen ${ }^{1 \dagger}$, Soumya Negi ${ }^{1}$, Derrick Cheng ${ }^{2}$, Zhengyu Ouyang ${ }^{2}$,

3 David Sexton ${ }^{1}$, Kejie Li ${ }^{1}$, Baohong Zhang ${ }^{1 *}$

4 Affiliations:

$5 \quad{ }^{1}$ Research Department, Biogen, Inc., 225 Binney St, Cambridge, MA 02142, USA

$6 \quad$ BBiolnfoRx, Inc., 510 Charmany Dr, Suite 275A, Madison, WI 53719, USA

7 Emails:

8 DL: dongdong.lin@biogen.com

9 YC: yirui.chen@biogen.com

10 SN: soumya.negi@biogen.com

11 DC: derrick@bioinforx.com

12 ZO: oyoung@bioinforx.com

13 DS: david.sexton@biogen.com

14 KL: kejie.li@biogen.com

15 BZ: baohong.zhang@biogen.com

16 T These authors contributed equally to this work

17 * Correspondence: Baohong Zhang, baohong.zhang@biogen.com 


\section{Abstract}

CellDepot serves as an integrated web application to assist users in exploring single-cell

21 RNA-seq (scRNA-seq) datasets and comparing the datasets among various studies through a

22 user-friendly interface with advanced visualization and analytical tools. To begin with, it provides

23 an efficient data management system that users can upload single cell datasets and query the

24 database by multiple attributes such as species and cell types. In addition, the advanced query

25 function incorporated in MySQL database system and its conditional filtering, allows users to

26 quickly query and compare the expression of gene(s) across the datasets of interest. Moreover,

27 by embedding the cellxgene VIP tool, CellDepot enables fast exploration of individual dataset in

28 the manner of interactivity and scalability to gain more refined insights such as cell composition,

29 gene expression profiles, and differentially expressed genes among cell types. In summary, the

30 web portal allows large scale single cell data sharing, analysis and visualization for supporting

31 decision-making, and encouraging scientists to contribute to the single-cell community in a

32 tractable and collaborative way. Finally, CellDepot is released as open-source software to

33 motivate crowd contribution, broad adoption, and local deployment for private data.

\section{Keywords}

36 Single cell, Single-cell RNAseq, cellxgene, data visualization, scRNA-seq portal 


\section{Introduction}

Since the first print of using next-generation sequencing technology to analyze the singlecell transcriptome in 2009 [1], this technology has massively ignited the interest in obtaining highresolution characterizations of each cell's transcriptome. Afterwards, an exponentially growing

41 number of studies utilized this advanced scRNA-seq technology to investigate the expression

42 changes among cells or groups from various sources such as cell lines, tissues, or species [2-5].

43 Meanwhile, substantial efforts have been invested in developing computational pipelines and

44 tools to advance the analysis and visualization of large-scale scRNA-seq data [6-10]. With more

45 scRNA-seq datasets have been published by community, it is urgent to launch some in-depth

46 investigations of the associations of those identified biological variations with cellular

47 heterogeneity. However, many datasets are from different studies or individual labs that are preprocessed in varied ways. Therefore, it is necessary to build a centralized space for managing, analyzing, and visualizing those datasets to yield comprehensive insights from this big data.

Several tools and databases have been built to store, analyze, and visualize scRNA-seq datasets, which allow scientists to compile and query the information at their hand. The 'Human Cell Atlas' consortium [11] leads an international collaboration to generates single-cell datasets

53 from human body tissues, which are manually curated and processed by a uniform pipeline.

54 'JingleBells' provides single-cell data [12] focusing on immune cells. The 'conquer' database 55 provides uniformly processed single-cell expression data to facilitate benchmarking of 56 computational tools [13]. The 'PanglaoDB' database provides single-cell RNA-seq count matrices

57 from public sequencing data in the National Center for Biotechnology Information Sequence Read

58 Archive [14]. The 'EMBL-EBI Single-Cell Expression Atlas' provides uniformly processed data

59 from submissions to 'ArrayExpress' [15]. The Broad Institute also offers a public 'Single-Cell

60 Portal' (https://singlecell.broadinstitute.org/single cell). Although those 'atlas' and portals have

61 greatly facilitated the exploration of single-cell datasets from the database [16-20], they usually 
62 tackle certain aspects of managing, visualizing, or analyzing scRNA-seq datasets with limitations

63 on both query and visualization functionalities. For comprehensive review of these portals,

64 detailed feature comparison is outlined in supplementary Table S1.

65 We developed a database-backed single cell portal available at

66 http://celldepot.bxgenomics.com with user-friendly interactive visualization and analysis

67 capabilities, namely CellDepot to empower biologists and bioinformaticians to manage, explore,

68 visualize, and compare scRNA-seq datasets in a comprehensive, flexible, and collaborative

69 manner.

\section{Results and Discussion}

1. Overview of CellDepot

CellDepot is a user-friendly centralized database platform that integrates the database management system along with the search engine. The web-based platform enables the share of scRNA-seq data and efficient communication among the community, which in turn encourages crowd contributions to the online scRNA-seq data portal. Currently, there are more than two hundred scRNA-seq datasets from eight species hosted on the portal for public access. Notably,

77 CellDepot integrates with advanced single-cell transcriptomic data explorer to conduct all analytical tasks on the webserver while presenting interactive results on the webpage through leveraging modern web development techniques (Figure 1a).

Highly unified space for managing, exploring, and analyzing comprehensive single-cell

81 datasets is one of the significant strengths of CellDepot. Nowadays, while a few web-based 82 portals for both visualizing and analyzing scRNA-seq datasets are available, they have limitations 83 on scalability and capability in comparing among various datasets to meet increasing demands

84 on examining single-cell RNA-seq datasets. CellDepot employs the MySQL relational database 85 management system, a robust scRNA-seq data visualization tool cellxgene [21], and its versatile 86 plugin cellxgene VIP [22] to allow project selection and filtering, scRNA-seq data visualization and 
87 analysis, and cross-project comparison of targeted genes as illustrated Figure $1 \mathrm{~b}$.

a

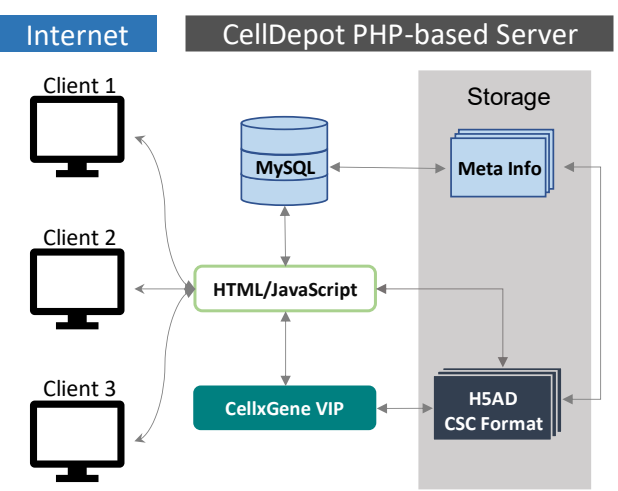

b

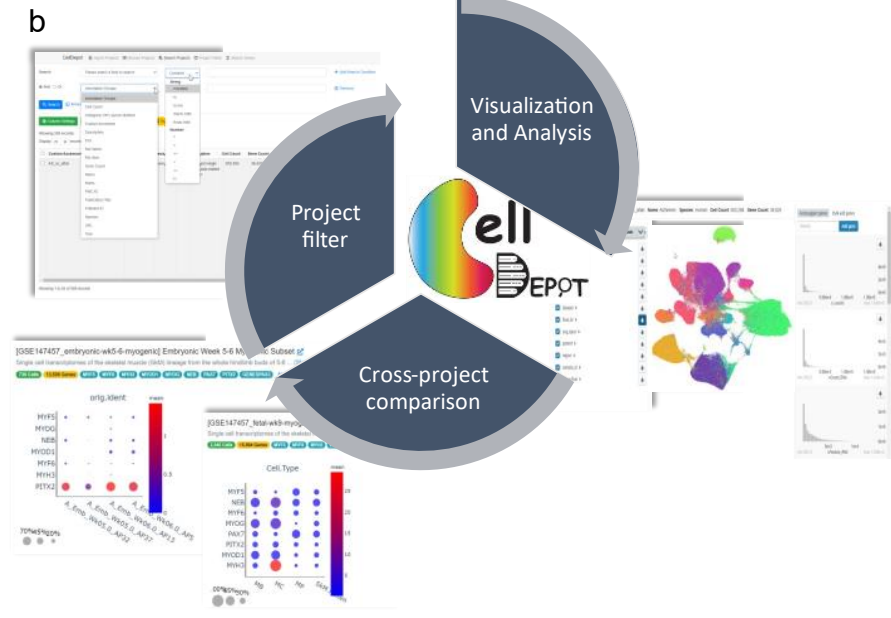

88

Figure 1. CellDepot portal overview. (a) The architecture of CellDepot. (b) Functional structure of CellDepot.

\section{Features of CellDepot}

There are mainly three functions built in the platform: project search/filter, visualization and analysis, and cross-project comparison, which will be discussed thoroughly in the following sections.

a. Data filtering scRNA-seq datasets are stored as h5ad files in the compressed sparse column (CSC) format and managed efficiently in the CellDepot together with the metadata table of projects. For each dataset, some primary metadata fields are inputted by users and can be updated as needed. The main CellDepot application consists of five functionalities:

- Importing projects provides a user-friendly way to upload processed public or private datasets in h5ad format.

- Browsing projects displays a quick overview of all datasets in CellDepot with a quick search function and customized column setting such that users can easily find the projects of interest, personalize the look-n-feel of the project table and export the customized project spreadsheet. 
- Searching projects enables advanced query of projects by joining multiple search conditions with the logical operators.

- Project filters refines the matched datasets by simply selecting 'Year' and/or 'Species'. It is a user-friendly feature for a first-time user who is not familiar with

- Searching genes allows users to input any gene(s) of interest and generate the cross-dataset plots for those targeted genes.

113 are extracted for searching and filtering, such as species, cell type annotation, published year,

114 etc. As shown in Figure S1, there are six datasets when searching by 'Species is Human' and 115 'Annotation Group contains Neuron'.

It is desirable to include all possible abbreviations and synonyms of genes or cell types in

117 the database to make search more flexible. In reality, CellDepot has not enumerated and 118 standardized all possible terms used to name cell types in the query function beyond metadata 119 collected from h5ad files. In the future, a comprehensive mapping table of terms based on cell 120 ontology could be implemented to standardize keywords for searching. Alternatively, user can 121 use advanced search function to query a cell type by multiple synonyms, e.g., searching by 122 'Annotation Groups contains OPC' or 'Annotation Groups contains oligodendrocyte' to identify 123 datasets containing oligodendrocyte cell type.

124 b. Data visualization and analysis

125 Users can launch a cellxgene VIP instance (such as dataset GSE140231) [23] as shown

126 in Figure 2 to explore a dataset interactively. Cellxgene VIP is based on the cellxgene platform

127 where users can quickly overview meta information and cell embedding after dimensional 128 reduction (e.g., TSNE or UMAP). In addition, users can use lasso selection from embedded cell 129 maps to interactively select any cell cluster(s) as a group for refined analysis via a rich set of 130 visualization and analysis functions provided in cellxgene VIP. 


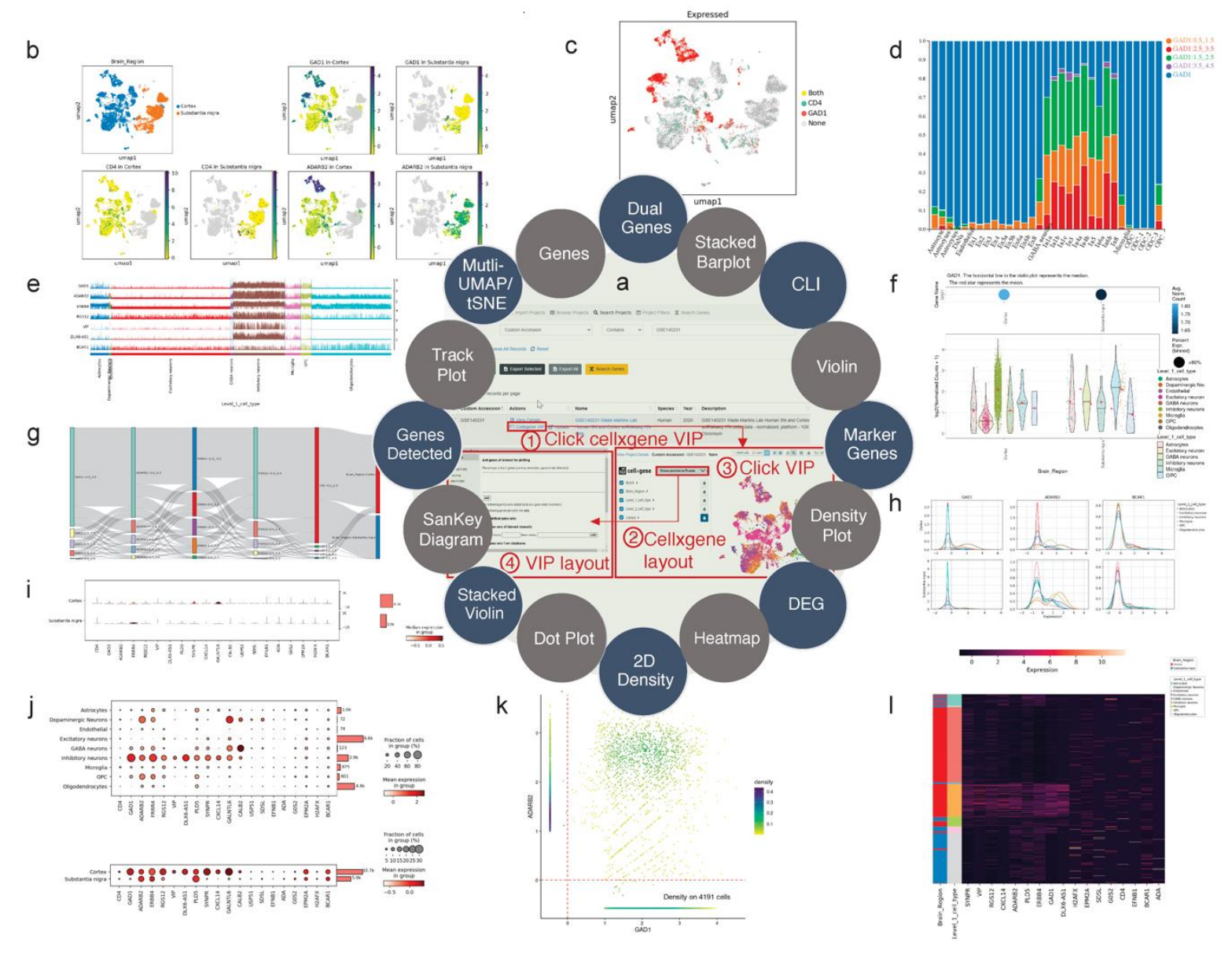

Figure 2. Exploration of visualization and analysis functions in cellxgene VIP on dataset GSE140231 [23]. (a)

Cellxgene VIP, providing a plugin ecosystem of interactive data visualization, can be launched within four steps after querying 'custom accession contains GSE140231'.

(b) Mutli-tSNE/UMAP plot shows the differential expression of genes on split brain regions. (c) Dual-gene plot demonstrates the expression of CD4 and GAD1 on the selected embedding layout. (d) Stacked barplot indicates the fraction of cell distribution of the selected gene over different cell types. (e) Trackplot represents the distribution of gene expression across individual cells in annotated clusters. (f) Sub-grouped violin plot shows the GAD1 gene expression across the groups of cell types and subgroups of the brain regions. (g) Sankey diagram illustrates the inter-dependent relationship of annotated clusters based on the selected genes. (h) Density plots show expression of marker gene across varied cell types and split across the brain regions. (i) Stacked violin plot highlights the selected cell markers over cell types.

(j) Dot plots highlights the gene

143 markers over different annotated clusters. (k) 2D-density plot illustrates the expression relationship of two genes

144 (GAD1 and ADARB2). (I) Heatmap of selected marker genes in various cell types. 
146 For example, user can go deep-dive to explore and visualize the expression of gene(s) across

147 the cluster of cells under various conditions (Figure S2). As shown in Figure S2a, two cell

148 groups from Astrocytes (1036 cells) and Oligodendrocytes (4417 cells) are selected. By running

149 differential analysis with one of the built-in statistical methods such as Welch's t-test, we

150 detected 1578 differential expressed genes (DEGs), including 715 up-regulated and 853 down-

151 regulated genes in astrocytes compared to oligodendrocytes (Figure S2a). The expression of

152 the top four DEGs among the cell types indicates that gene MBP, ST18 and RNF220 are

153 expressed explicitly in oligodendrocytes, while gene PITPNC3 is expressed mainly in astrocytes

154 and endothelial cells (Figure S2b). In the future, we plan to add other multi-omics data

155 modalities, which can be incorporated and integrated with scRNA-seq, such as spatial

156 transcriptomics and ScATAC-seq data.

c. Cross-dataset query

Besides the function to visualize and explore individual datasets, CellDepot also allows

users to query and compare the expression of genes of interest across multiple datasets to

understand their cellular heterogeneity. As shown in Figure 3, users can explore the expression

of skeletal muscle marker genes PAX3, PAX7, PITX2, MYF5, MYF6, MYOD1, MYOG, NEB,

weeks to fetal 9-18 weeks from datasets whose custom accession starting with GSE147457

164 [24]. Gene expression level in SkM cells highlighted by grey boxes in of Figure 3e decreases

165 around $40 \%$ from week 4 to week 5 with hx-protocol until level-off at week 6 . The expression

166 level of genes in fetal stage over week 9 also shows the same trend, especially the gene

167 expression level drops dramatically starting from week 12.

168 In summary, CellDepot is an easy-to-use and elaborative web portal for the exploration of

169 the scRNA-seq datasets and data analysis results such that it allows biologists to easily access

170 and reuse the rapid-increased scRNA-seq datasets in a highly scalable and interactive manner. 

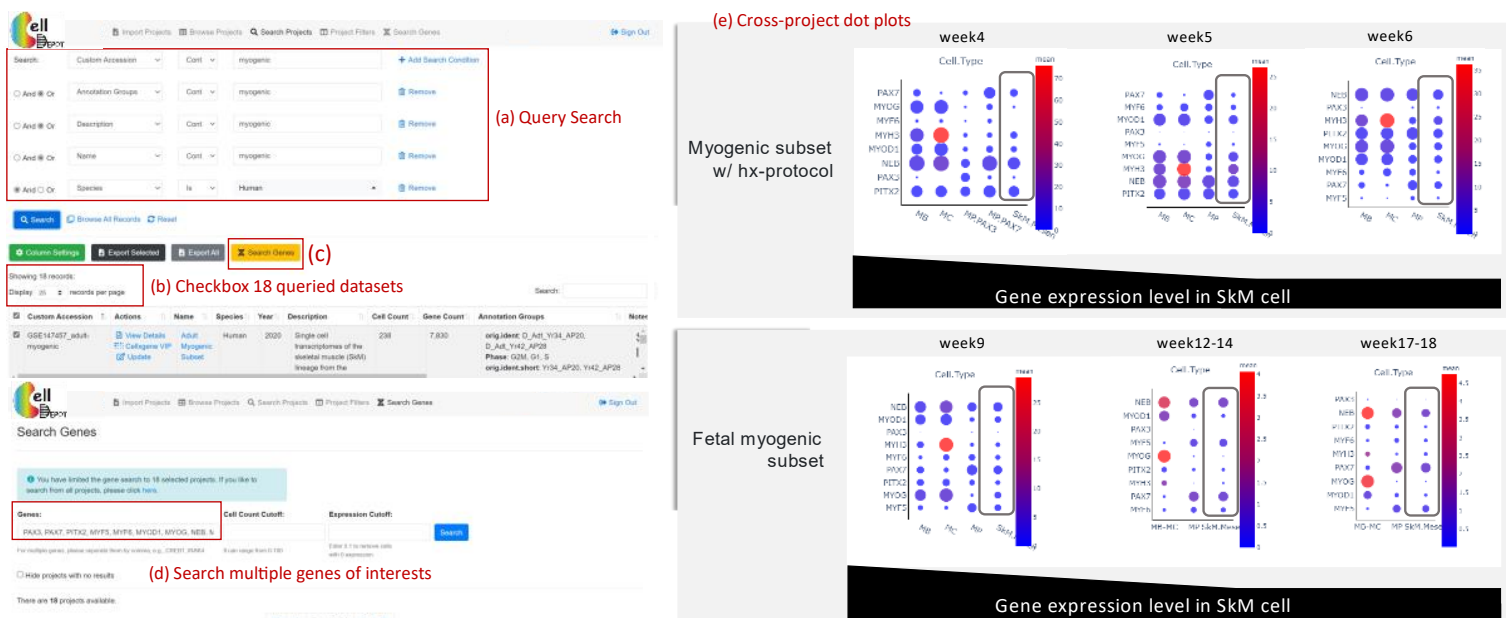

Figure 3. Cross-project view of the expression of genes among skeletal muscle development and differentiation times. (a) Search

and (b) select the targeted datasets whose custom accession starting with GSE147457 [24]. Navigate to (c) 'Search Genes' page

and (d) search genes of interest. (e) The summary of interactive plots from CellDepot that shows the cross-project comparison of

gene expression level under varied conditions.

Materials and Methods

Sources of annotation and metadata

The original metadata information of each single cell RNA-seq dataset is retrieved from

h5ad file, which is a preferred way of sharing and storing an on-disk representation of anndata

object [6]. When importing the dataset to the system, user inputs additional metadata

information as shown in Figure S5. Both metadata are collected and stored in a MySQL

database table that is presented at http://celldepot.bxgenomics.com.

Data format, availability and preparation

CellDepot requires scRNA-seq data in h5ad file where the expression matrix is stored in CSC (compressed sparse column) instead of CSR (compressed sparse row) format to improve the speed of data retrieving. For example, designating genes as columns in the h5ad file

187 creates the interactive plot five times faster than as rows. Just in case, we provide sample

188 scripts to help users generate h5ad files. Having gene expression matrix, metadata, and layout 189 files, users can easily combine and convert their data to h5ad file by following this R script on 
https://github.com/interactivereport/CellDepot/blob/main/toH5ad.R. In the case of lacking layout

191 file, users can also create h5ad file by following the Jupyter notebook

192 https://github.com/interactivereport/CellDepot/blob/main/raw2h5ad.ipynb with custom python

193 script tailored to their own data. Categorical features extracted from a h5ad file are shown in the

194 'annotation groups' column of the table on CellDepot home page, while the numerical features

195 are shown as the distributions in the rightmost panel on cellxgene VIP (Figure S3).

\section{6}

197

198

199

200

201

202

203

204

205

206

207

208

209

210

211 uploaded, CellDepot will automatically convert the dataset to CSC format if needed through a

212 cron job (Supplementary Tutorial Section 5). To explore the detail of imported datasets, users

213 can enter 'Browse Projects' page and then search these datasets by user assigned accessions

214 in the metadata file. 
The CellDepot API web service provides a direct way to generate figures for users to

217 share or embed in web page. For example, the following URL will generate a gene expression

218 violin plot across cell clusters for IRAK4 gene for the data set with ID equaling one,

219 https://celldepot.bxgenomics.com/celldepot/app/core/api gene plot.php?ID=1\&Genes=IRAK4\&

220 Plot Type=violin\&Subsampling $=0 \& n=0 \& g=0 \&$ Project Group $=$ CLUSTER . The complete format

221 of the URL and explanation of parameters are detailed in the web page,

222 https://celldepot.bxgenomics.com/celldepot manual/api gene plot.php.

\section{Code availability}

The source code, local installation guide and complete tutorial of visualization and analysis tool are provided at https://github.com/interactivereport/CellDepot. With broad adoption

226 and contribution in mind, CellDepot is released under the MIT License.

\section{Author Contributions}

228 Dongdong Lin: Conceptualization, Methodology, Manuscript - writing \& review

229 Yirui Chen: Testing, Manuscript - writing, review \& editing

230 Kejie Li: Conceptualization, Testing, Manuscript - review \& editing

231 Soumya Negi: Methodology, Testing, Manuscript - review \& editing

232 Derrick Cheng: Web application development, Manuscript - review

233 Zhengyu Ouyang: Data curation, Manuscript - review

234 David Sexton: Conceptualization, Manuscript - review

235 Baohong Zhang: Conceptualization, Testing, Methodology, Manuscript - writing, review \& 236 editing

\section{Declaration of competing interest}

238 DL, KL, SN, DS and BZ hold Biogen stocks as Biogen employee. 


\section{Acknowledgements}

240 The authors are grateful and indebted to BiolnfoRx, Inc. for the management of server and

241 storage to host the public web site.

\section{References}

244 1. Tang F, Barbacioru C, Wang Y, Nordman E, Lee C, Xu N, et al., (2009). mRNA-Seq whole-

245 transcriptome analysis of a single cell. Nat Methods 6, 377-82.

246 2. Katzenelenbogen Y, Sheban F, Yalin A, Yofe I, Svetlichnyy D, Jaitin DA, et al., (2020).

247 Coupled scRNA-Seq and Intracellular Protein Activity Reveal an Immunosuppressive Role of

248 TREM2 in Cancer. Cell 182, 872-85 e19.

249 3. Madissoon E, Wilbrey-Clark A, Miragaia RJ, Saeb-Parsy K, Mahbubani KT, Georgakopoulos

250 N, et al., (2019). scRNA-seq assessment of the human lung, spleen, and esophagus tissue

251 stability after cold preservation. Genome Biol 21, 1.

252 4. Wang Z, Xu X. (2020). scRNA-seq Profiling of Human Testes Reveals the Presence of the

253 ACE2 Receptor, A Target for SARS-CoV-2 Infection in Spermatogonia, Leydig and Sertoli Cells.

254 Cells 9.

255 5. Qi J, Zhou Y, Hua J, Zhang L, Bian J, Liu B, et al., (2021). The scRNA-seq Expression

256 Profiling of the Receptor ACE2 and the Cellular Protease TMPRSS2 Reveals Human Organs

257 Susceptible to SARS-CoV-2 Infection. Int J Environ Res Public Health 18.

258 6. Wolf FA, Angerer P, Theis FJ. (2018). SCANPY: large-scale single-cell gene expression data 259 analysis. Genome Biol 19, 15.

260 7. Satija R, Farrell JA, Gennert D, Schier AF, Regev A. (2015). Spatial reconstruction of single261 cell gene expression data. Nat Biotechno/ 33, 495-502.

262 8. Butler A, Hoffman P, Smibert P, Papalexi E, Satija R. (2018). Integrating single-cell 263 transcriptomic data across different conditions, technologies, and species. Nat Biotechno/ 36, $264 \quad 411-20$. 
9. Stuart T, Butler A, Hoffman P, Hafemeister C, Papalexi E, Mauck WM, 3rd, et al., (2019). Comprehensive Integration of Single-Cell Data. Cell 177, 1888-902 e21.

267 10. Hao Y, Hao S, Andersen-Nissen E, Mauck WM, 3rd, Zheng S, Butler A, et al., (2021).

268 Integrated analysis of multimodal single-cell data. Cell 184, 3573-87 e29.

269 11. Regev A, Teichmann SA, Lander ES, Amit I, Benoist C, Birney E, et al., (2017). The Human 270 Cell Atlas. Elife 6.

271 12. Ner-Gaon H, Melchior A, Golan N, Ben-Haim Y, Shay T. (2017). JingleBells: A Repository of 272 Immune-Related Single-Cell RNA-Sequencing Datasets. J Immunol 198, 3375-9.

273 13. Soneson C, Robinson MD. (2018). Bias, robustness and scalability in single-cell differential 274 expression analysis. Nat Methods 15, 255-61.

275 14. Franzen O, Gan LM, Bjorkegren JLM. (2019). PanglaoDB: a web server for exploration of 276 mouse and human single-cell RNA sequencing data. Database (Oxford) 2019.

277 15. Papatheodorou I, Moreno P, Manning J, Fuentes AM, George N, Fexova S, et al., (2020).

278 Expression Atlas update: from tissues to single cells. Nucleic Acids Res 48, D77-D83.

279 16. Bernstein MN, Ni Z, Collins M, Burkard ME, Kendziorski C, Stewart R. (2020). CHARTS: A 280 web application for characterizing and comparing tumor subpopulations in publicly available 281 single-cell RNA-seq datasets. 2020.09.23.310441.

282 17. Orvis J, Gottfried B, Kancherla J, Adkins RS, Song Y, Dror AA, et al., (2021). gEAR: Gene 283 Expression Analysis Resource portal for community-driven, multi-omic data exploration. Nat 284 Methods 18, 843-4.

285 18. Cai G, Xiao F. (2020). SCANNER: A Web Server for Annotation, Visualization and Sharing 286 of Single Cell RNA-seq Data, bioRxiv 2020.01.25.919712 [Preprint], doi:

287 https://doi.org/10.1101/2020.01.25.919712.

288 19. Darde TA, Lecluze E, Lardenois A, Stevant I, Alary N, Tuttelmann F, et al., (2019). The 289 ReproGenomics Viewer: a multi-omics and cross-species resource compatible with single-cell 290 studies for the reproductive science community. Bioinformatics 35, 3133-9. 
291 20. Cao Y, Zhu J, Han G, Jia P, Zhao Z. (2017). scRNASeqDB: a database for gene expression 292 profiling in human single cell by RNA-seq. 104810.

293 21. Megill C, Martin B, Weaver C, Bell S, Prins L, Badajoz S, et al., (2021). cellxgene: a

294 performant, scalable exploration platform for high dimensional sparse matrices, bioRxiv

295 2021.04.05.438318 [Preprint], doi: https://doi.org/10.1101/2021.04.05.438318

296 22. Li K, Ouyang Z, Lin D, Mingueneau M, Chen W, Sexton D, et al., (2020). cellxgene VIP

297 unleashes full power of interactive visualization, plotting and analysis of scRNA-seq data in the

298 scale of millions of cells, bioRxiv 2020.08.28.270652 [Preprint], doi:

299 https://doi.org/10.1101/2020.08.28.270652.

300 23. Agarwal D, Sandor C, Volpato V, Caffrey TM, Monzon-Sandoval J, Bowden R, et al., (2020).

301 A single-cell atlas of the human substantia nigra reveals cell-specific pathways associated with

302 neurological disorders. Nat Commun 11, 4183.

303 24. Xi H, Langerman J, Sabri S, Chien P, Young CS, Younesi S, et al., (2020). A Human

304 Skeletal Muscle Atlas Identifies the Trajectories of Stem and Progenitor Cells across

305 Development and from Human Pluripotent Stem Cells. Cell Stem Cell 27, 181-5. 
bioRxiv preprint doi: https://doi.org/10.1101/2021.09.30.462602; this version posted October 1, 2021. The copyright holder for this preprint (which was not certified by peer review) is the author/funder, who has granted bioRxiv a license to display the preprint in perpetuity. It is made available under aCC-BY-NC-ND 4.0 International license.

\section{Supplementary Information}

\section{Supplementary Tables}

Table S1. Comparison matrix of web portal tools

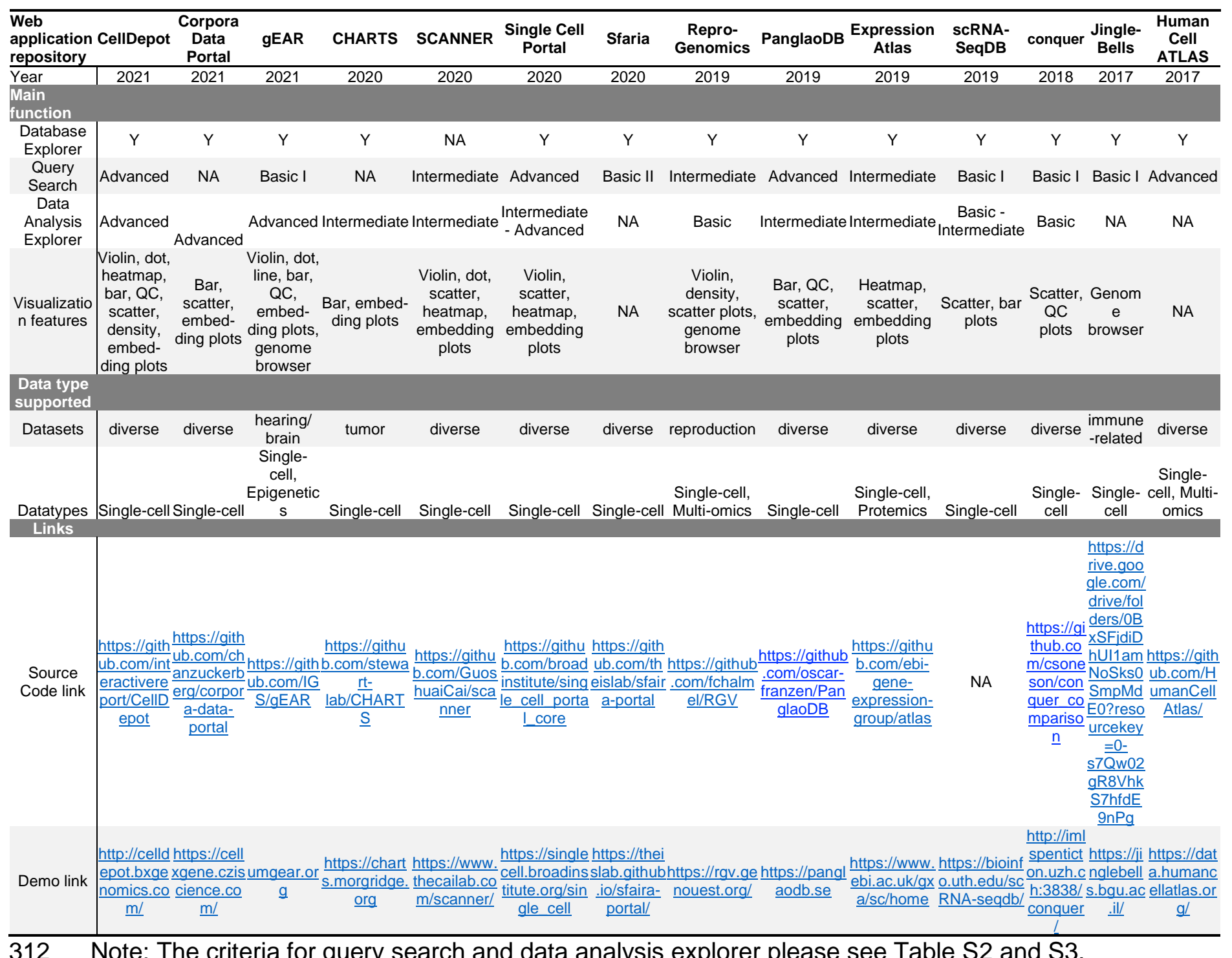


bioRxiv preprint doi: https://doi.org/10.1101/2021.09.30.462602; this version posted October 1 2021. The copyright holder for this preprint (which was not certified by peer review) is the author/funder, who has granted bioRxiv a license to display the preprint in perpetuity. It is made available under aCC-BY-NC-ND 4.0 International license.

314

315

316

Table S2. Criterion for query search

\begin{tabular}{l|lll}
\hline Query Search & Keyword Search & Multiple Object Search & Category Filters \\
\hline Basic & $Y$ & & \\
Intermediate & $Y$ & & Y \\
Advanced & $Y$ & $Y$ & Y \\
\hline
\end{tabular}

Table S3. Criterion for data analysis explorer

Table S4. Project metadata captured in CellDepot

\begin{tabular}{|c|c|c|c|}
\hline Data Analysis Explorer & $\begin{array}{l}\text { Visualization and Analyze } \\
\text { scRNA-seq Data }\end{array}$ & $\begin{array}{l}\text { Visualization and Analyze } \\
\text { scRNA-seq Data } \\
\text { Analyze Gene Expression }\end{array}$ & Customize Displays \\
\hline Basic & Y & & \\
\hline Intermediate & Y & $\mathrm{Y}$ & \\
\hline Advanced & Y & $Y$ & $\mathrm{Y}$ \\
\hline
\end{tabular}

General

\begin{tabular}{|c|c|c|c|}
\hline & $\begin{array}{l}\text { General } \\
\text { Category }\end{array}$ & Variable type & Description \\
\hline \multirow{17}{*}{ Project Browser/Search } & $\begin{array}{l}\text { Annotation } \\
\text { Groups }\end{array}$ & String & categorical features from h5ad file \\
\hline & Cell Count & Integer & numbers of cell in study \\
\hline & Actions & Link & $\begin{array}{l}\text { three options: } \\
\text { 1) Study summary information } \\
\text { 2) Data visualization and analysis } \\
\text { 3) Update project information }\end{array}$ \\
\hline & $\begin{array}{l}\text { Custom } \\
\text { Accession }\end{array}$ & String & $\begin{array}{l}\text { Customized accession name for individual } \\
\text { project }\end{array}$ \\
\hline & Description & String & Additional information \\
\hline & DOI & Link & Digital Object Identifier \\
\hline & File Name & String & h5ad file name \\
\hline & File Size & Integer & size of h5ad file \\
\hline & Gene Count & Integer & numbers of gene in study \\
\hline & Name & Link & project name \\
\hline & Notes & String & study notes \\
\hline & PMC ID & Link & \\
\hline & Publication Title & String & \\
\hline & PubMed ID & Link & \\
\hline & Species & String & \\
\hline & URL & Link & \\
\hline & Year & String & \\
\hline
\end{tabular}


bioRxiv preprint doi: https://doi org/10.1101/2021.09.30.462602; this version posted October 1 2021. The copyright holder for this preprint (which was not certified by peer review) is the author/funder, who has granted bioRxiv a license to display the preprint in perpetuity. It is made available under aCC-BY-NC-ND 4.0 International license.

Supplementary Figures

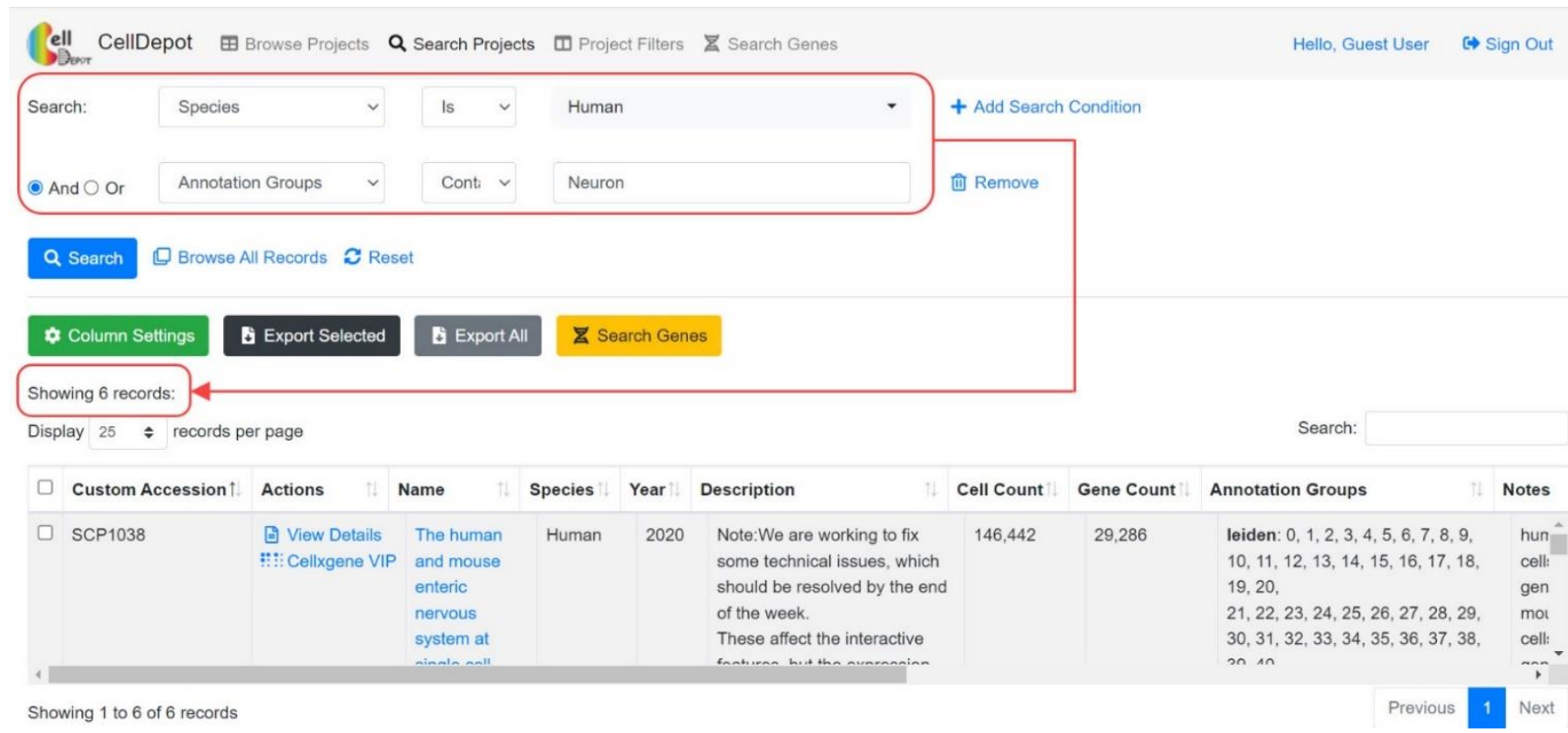

Figure S1. Data Filtering. Query search of 'Species is Human' and 'Annotation Groups contains Neuron' brings about nine datasets of interest.

a

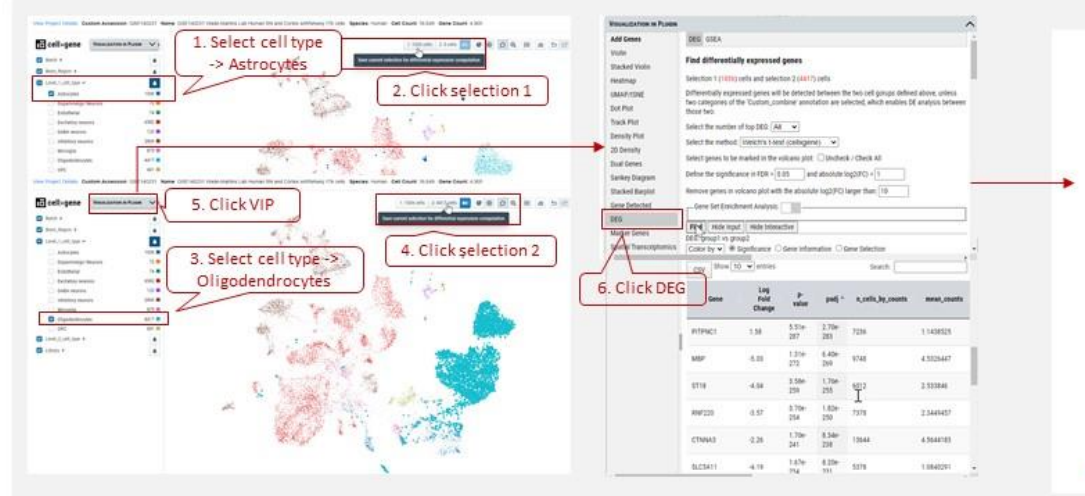

Differential expressed genes in astrocytes and oligodendrocytes

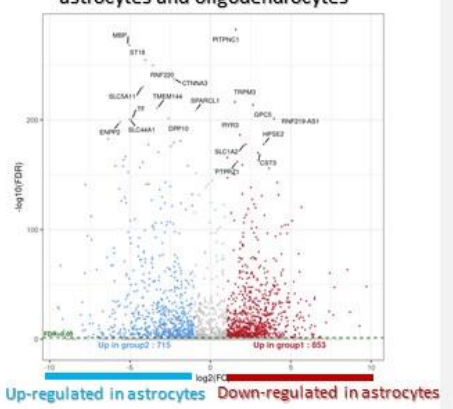

b

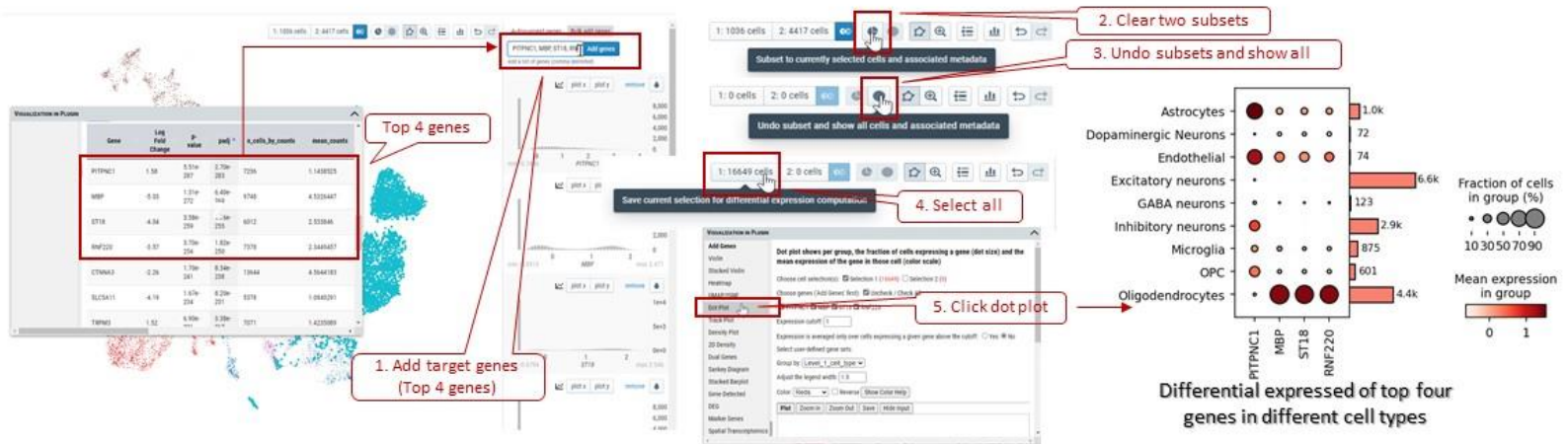

Figure S2. Exploration of differential expressed genes in dataset GSE140231 through cellxgene VIP [1]. (a) Differential expressed genes in astrocytes and oligodendrocytes. (b) The expression of top four genes in different cell types. 


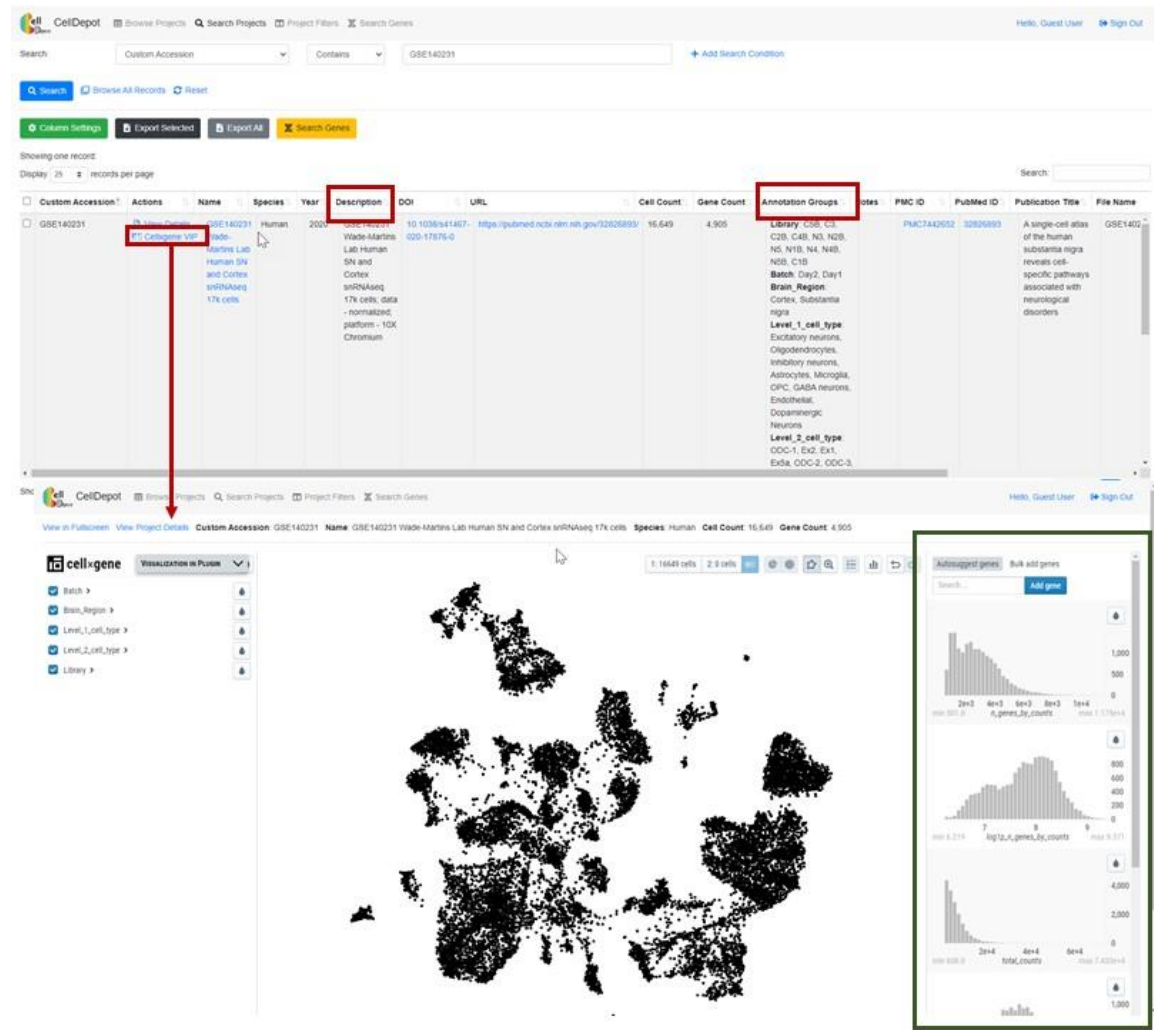

The annotation of the observation features from GSE140231.h5ad: Index(['Library', 'Batch', 'Brain_Region', 'Level_1_cell_type', 'Level_2_cell_type', 'percent_mito', 'n_genes_by_counts', 'log1p_n_genes_by_counts', 'total_counts', 'log1p_total_counts', 'pct_counts_in_top_50_genes', 'pct_counts_in_top_100_genes', 'pct_counts_in_top_200_genes', 'pct_counts_in_top_500_genes', '>Description'], dtype='object')

Figure S3. The exploration of observation features of dataset GSE140231. Red-marked categorical marked in green color can be visualized as distribution plots on the rightmost panel in cellxgene VIP tool, which is highlighted by green box. 


\section{Supplementary Tutorial}

1. Introduction

CellDepot is database management system integrated with management system, query searching and data visualization tools [2, 3] for scRNA-seq datasets, which can be accessed by the link http://celldepot.bxgenomics.com. This is a supplemental tutorial provides a detailed guide.

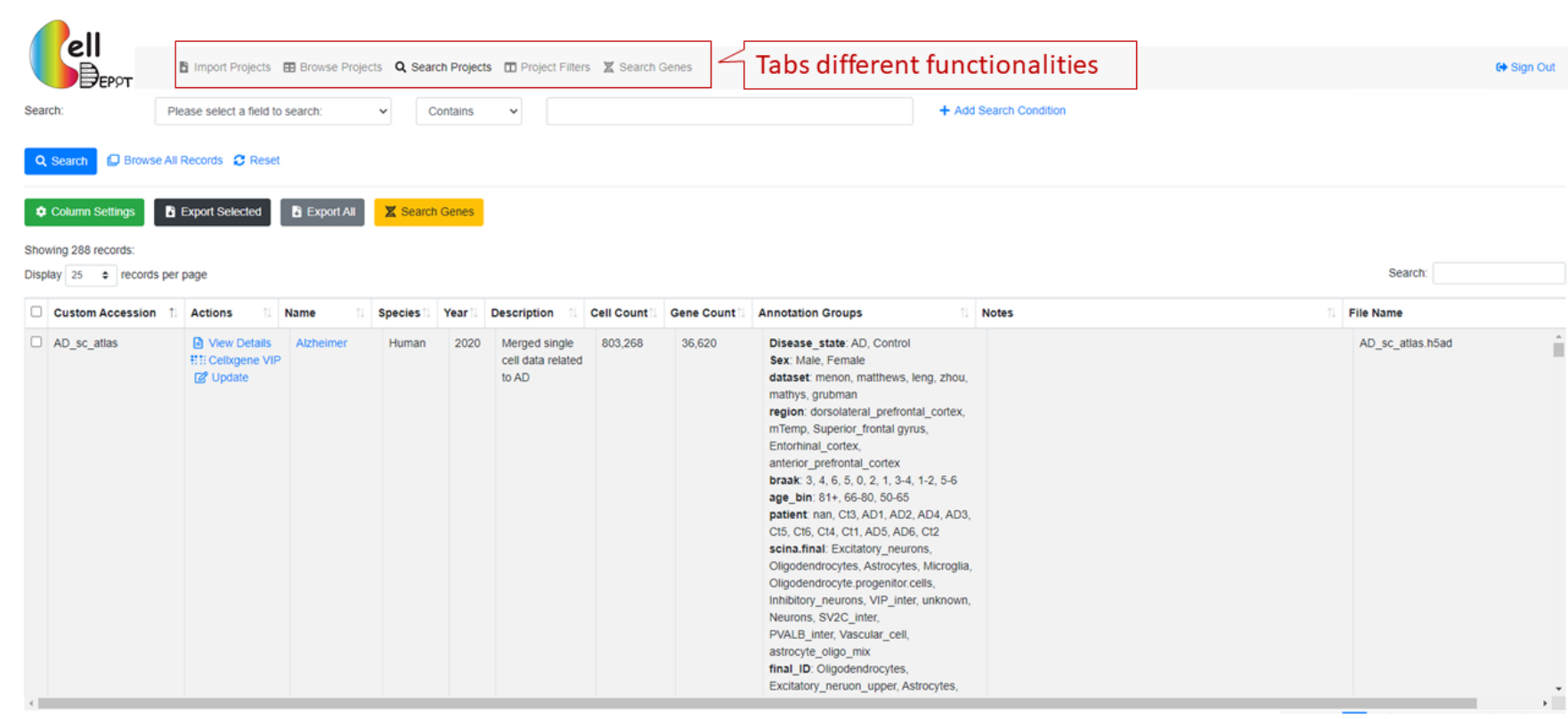

Figure S4. CellDepot website.

The interface contains multiple tabs, corresponding to import and/or select objects in CellDepot scRNAseq database, that can be accessed on top panel of the webpage. Users can upload their own dataset or explore the existing datasets for visualization and analysis.

\section{Upload Projects}

To upload new projects in CellDepot database, two files are required: 1) .h5ad files and 2) project information in csv format. Detailed formatting guidance can be found by 'Download Example File' hyperlink on webpage. In addition, two cellxgene VIP launch methods are provided: standard and preload in memory. Standard mode is for the first-time imported datasets, while preload in memory should be chosen when users update the meta information of datasets.

After the projects are submitted, CellDepot will automatically analyze the datasets. To explore the detail of uploaded datasets, users can navigate to 'browse projects' page and then search the imported datasets by the customized accession number. 


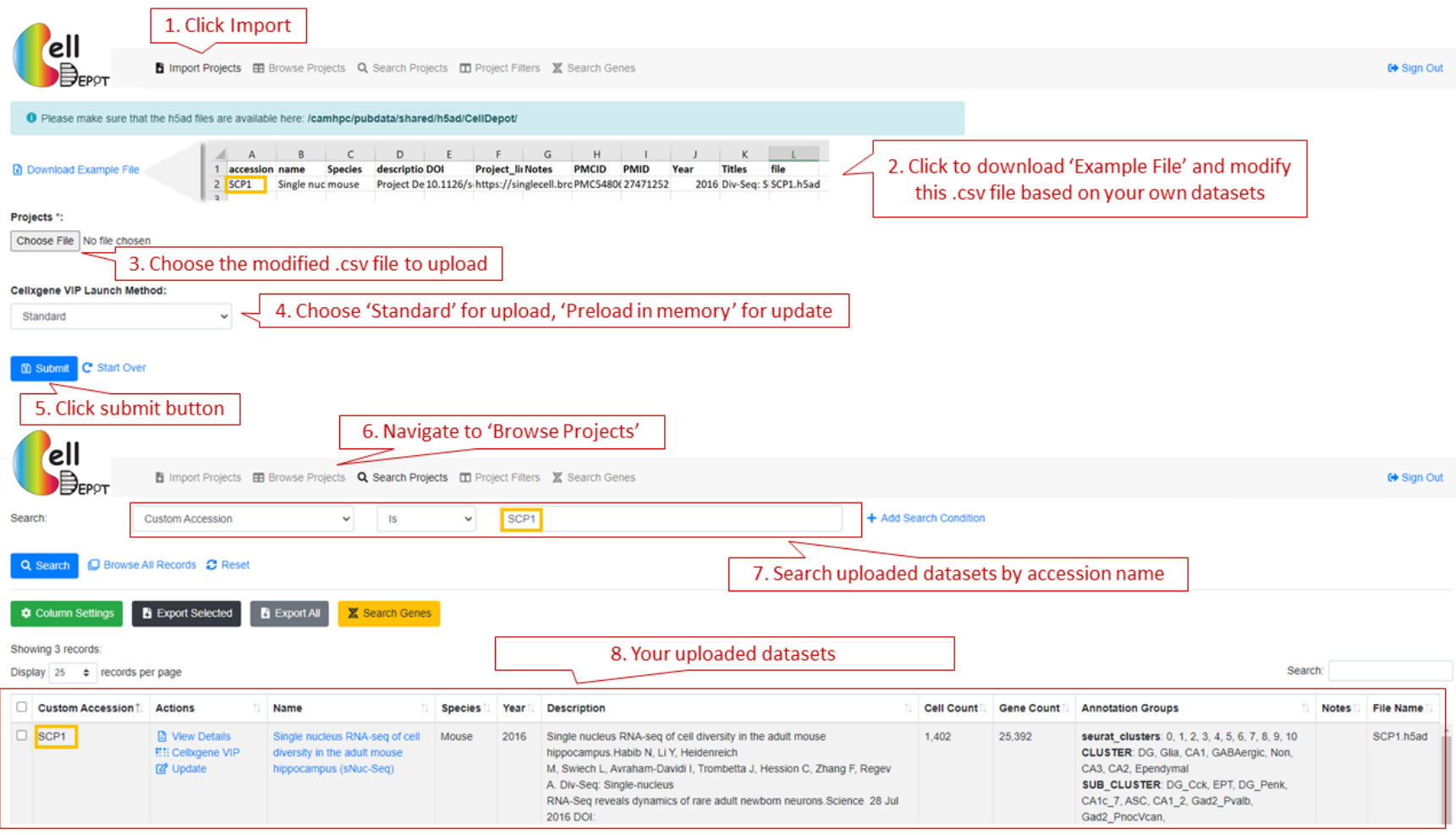

Figure S5. Workflow of how to import personal datasets.

\section{Browse Projects}

\section{Search Projects}

This function allows the user to search any targeted interests, which also can be accessed through search projects on the top panel of the webpage. Users is allowed to select the projects by 17 attributes: annotation groups, cell count, cellxgene VIP launch method, Custom accession, description, DOI, file name, file size, gene count, name, notes, PMC ID, Publication Title, PubMed ID, Species, URL, Year. These 17 fields can also be (partially) displayed on the webpage through 'column setting' on the webpage. Users can also search projects by the keywords via the search function on the right of the webpage. In addition, by 'column setting', users can set up the customized layout of targeted projects; thereby exporting to csv format.

For each project, users can view the datasets information, visualize data analysis, and conduct update through clicking on "View Details", "cellxgene VIP", and "Update" links, respectively. 
bioRxiv preprint doi: https://doi. org/10.1101/2021.09.30.462602. this version posted October 1 2021. The copyright holder for this preprint (which was not certified by peer review) is the author/funder, who has granted bioRxiv a license to display the preprint in perpetuity. It is made available under aCC-BY-NC-ND 4.0 International license.

376

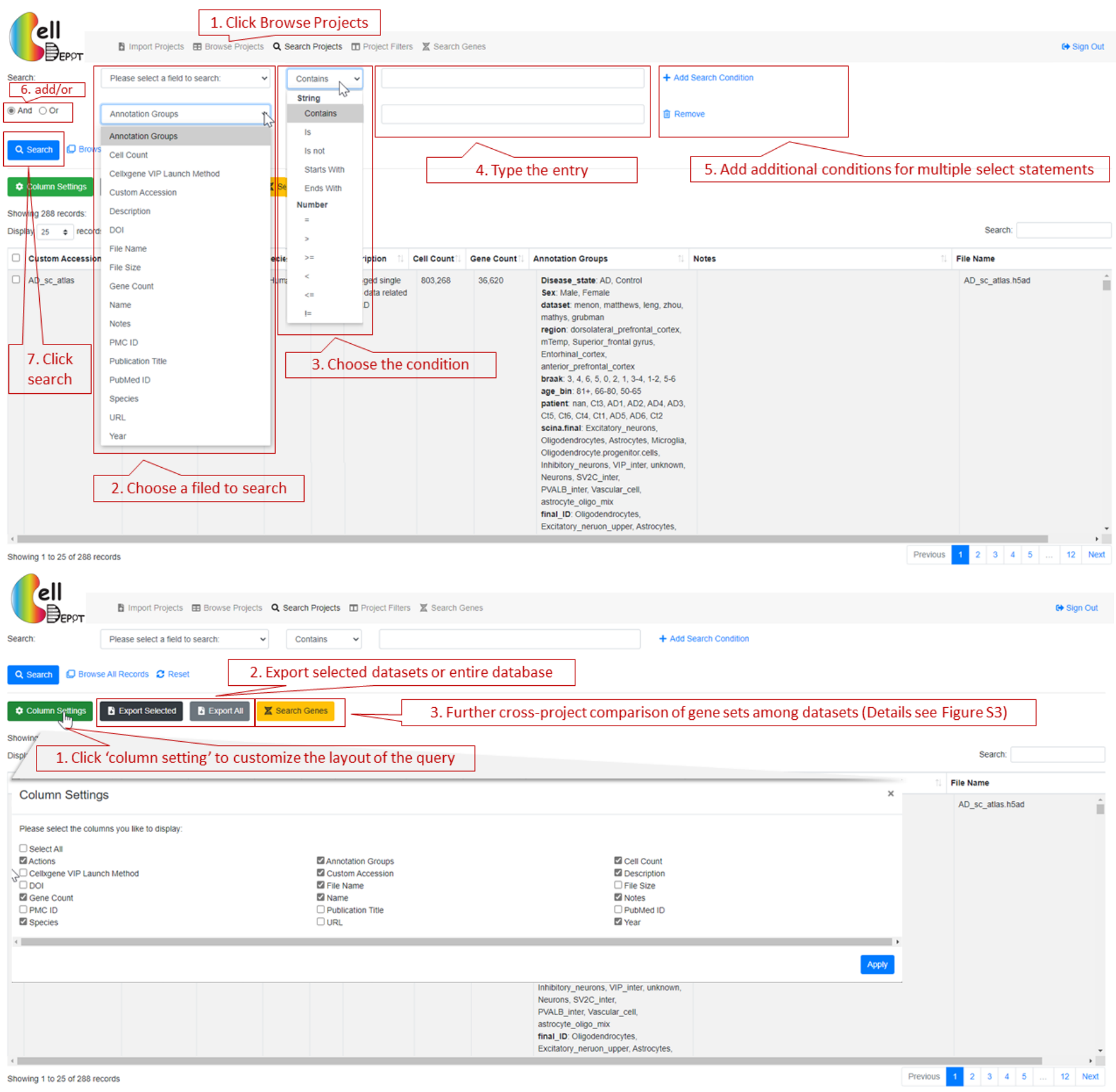

Figure S6. Workflow of how to search query on 'Browse Projects' page.

2. Case Study 1

Cross-project comparison of skeletal muscle marker genes PAX3, PAX7, PITX2, MYF5, MYF6, MYOD1, MYOG, NEB, and MYH3 among the datasets whose species is human and cell type is myogenic. 
bioRxiv preprint doi: https://doi. org/10.1101/2021.09 30.462602. this version posted October 1 2021. The copyright holder for this preprint (which was not certified by peer review) is the author/funder, who has granted bioRxiv a license to display the preprint in perpetuity. It is made available under aCC-BY-NC-ND 4.0 International license.

\begin{tabular}{|c|c|c|c|c|c|c|}
\hline $\mathrm{Z}_{\mathrm{Z}}$ & D import & rojects & 由 Brows & - Projects & ts Q Search Projects $\mathbb{C}$ Project Fiters & $\mathbf{z}$ Search Genes \\
\hline Search: & Custom Accession & $\checkmark$ & Cont $\sqrt{2}$ & $\checkmark$ & myogenic & + Add Search Condison \\
\hline$O$ And $\&$ or & Annotason Groups & $\checkmark$ & Cont - & 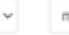 & myogenic & D Remove \\
\hline$O$ And $\bullet O r$ & Description & $\checkmark$ & cons & $\checkmark$ & myogenic & A Remove \\
\hline$O$ And $\bullet \circ$ & Name & $\checkmark$ & cont & $\checkmark$ & myogenic & A Ramove \\
\hline SAnd $O O O$ & Species & $\checkmark$ & is & $\checkmark$ & Muman & a Remove \\
\hline
\end{tabular}

Q Search 9 Bromse Al Records $\approx$ Reset

\section{a Column Sotthos Dexport Soloctod D Export At $\mathbf{Z}$ Soscch Genes}

Showing 18 records:

Display as o records per page

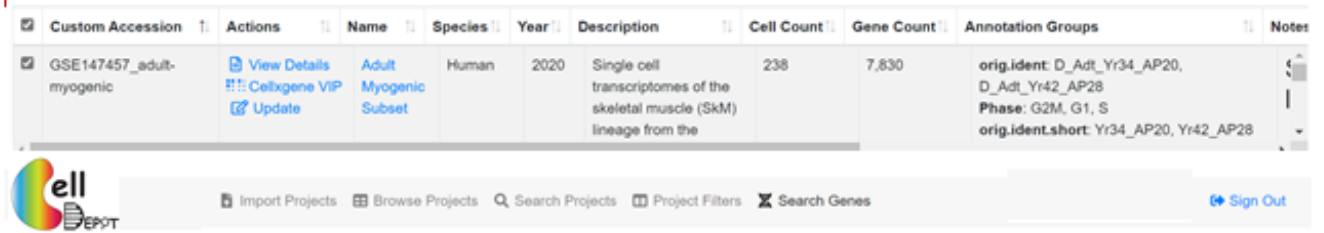

Search Genes

- You have limtod the gene search to 18 selected projocts. If you the to search from al projects, please cilck hero.

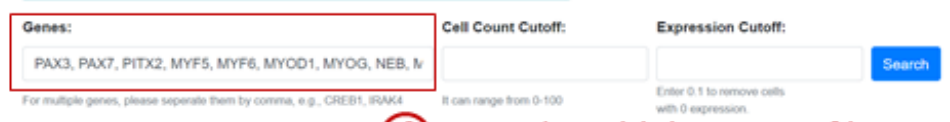

O Hiso projects with no resules

(4) Search multiple genes of interests

Thece ate 18 projocts avalation.

« \& Pago 10 ot 4 , "

[GSE147457_embryonic-wk5-6-myogenic] Embryonic Week 5-6 Myogenic Subset [C

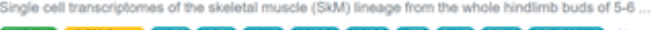

(5) Study 1: Week 4-6

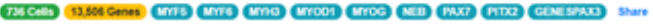
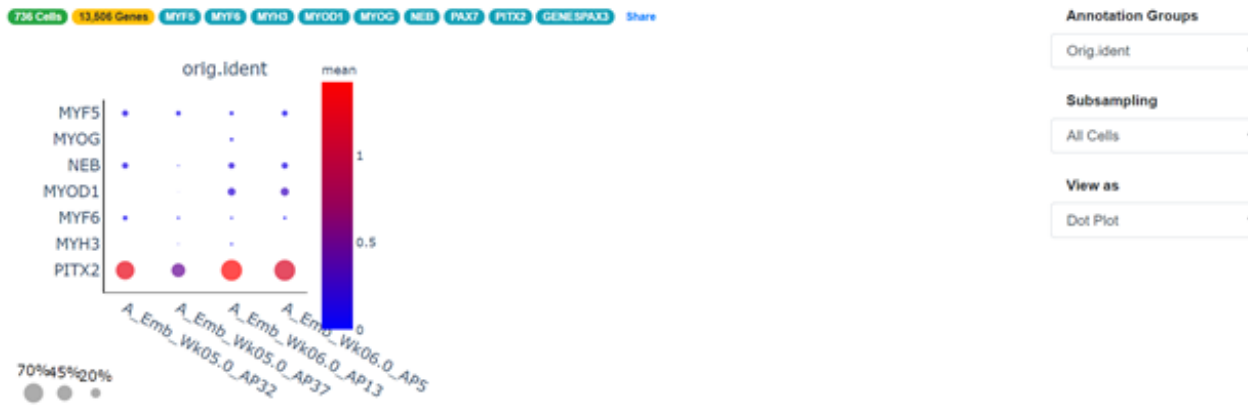

[GSE147457_fetal-wk9-myogenic] Fetal Week 9 Myogenic Subset $\mathbb{Z}$

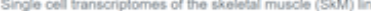

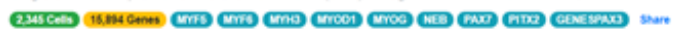

(6) Study 2: Week 9
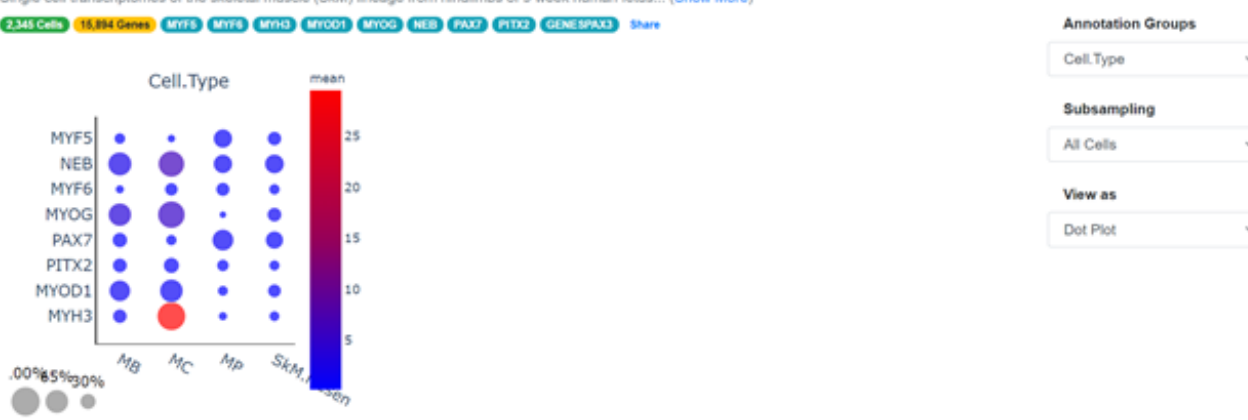
Figure S7. Workflow of how to conduct the cross-project comparison of gene sets among the selected datasets.

3. Project Filters

This page provides the matched datasets by simply clicking the categories. It is a first-time user-friendly functionality as users may not be familiar with the content of the database. The advance search function is the same as that on the 'Browse Projects' page (Details see Figure S4).

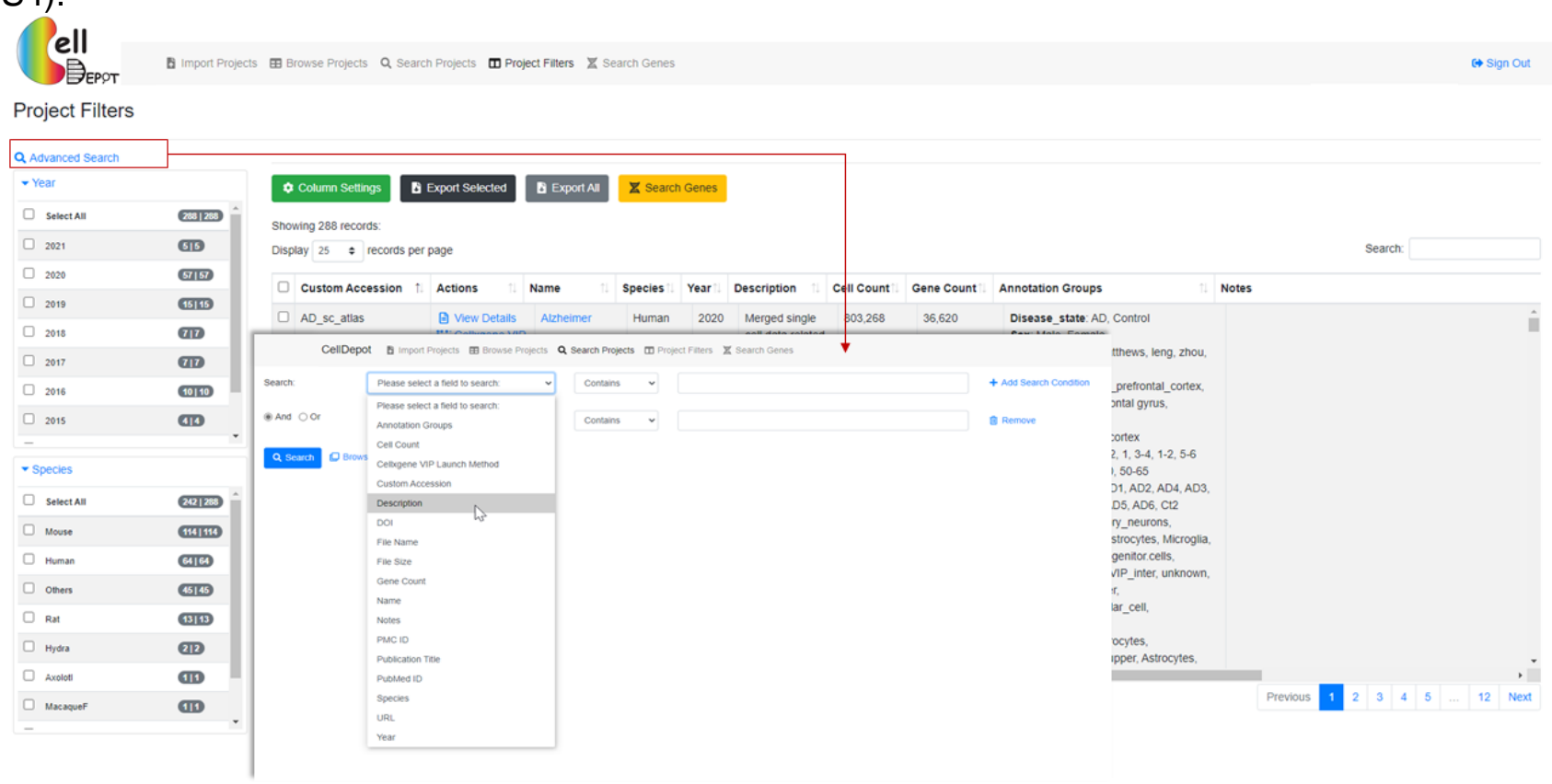

Figure S8. The layout of 'Project Filters' page.

\section{Visualize Datasets}

4.1 View Details

The datasets information consists of project summary and annotation groups. The project summary is provided by each user when uploading projects. The information of annotation groups is retrieved from uploaded .h5ad file. 
bioRxiv preprint doi: https://doi.org/10.1101/2021.09.30.462602; this version posted October 1 2021. The copyright holder for this preprint (which was not certified by peer review) is the author/funder, who has granted bioRxiv a license to display the preprint in perpetuity. It is made available under aCC-BY-NC-ND 4.0 International license.

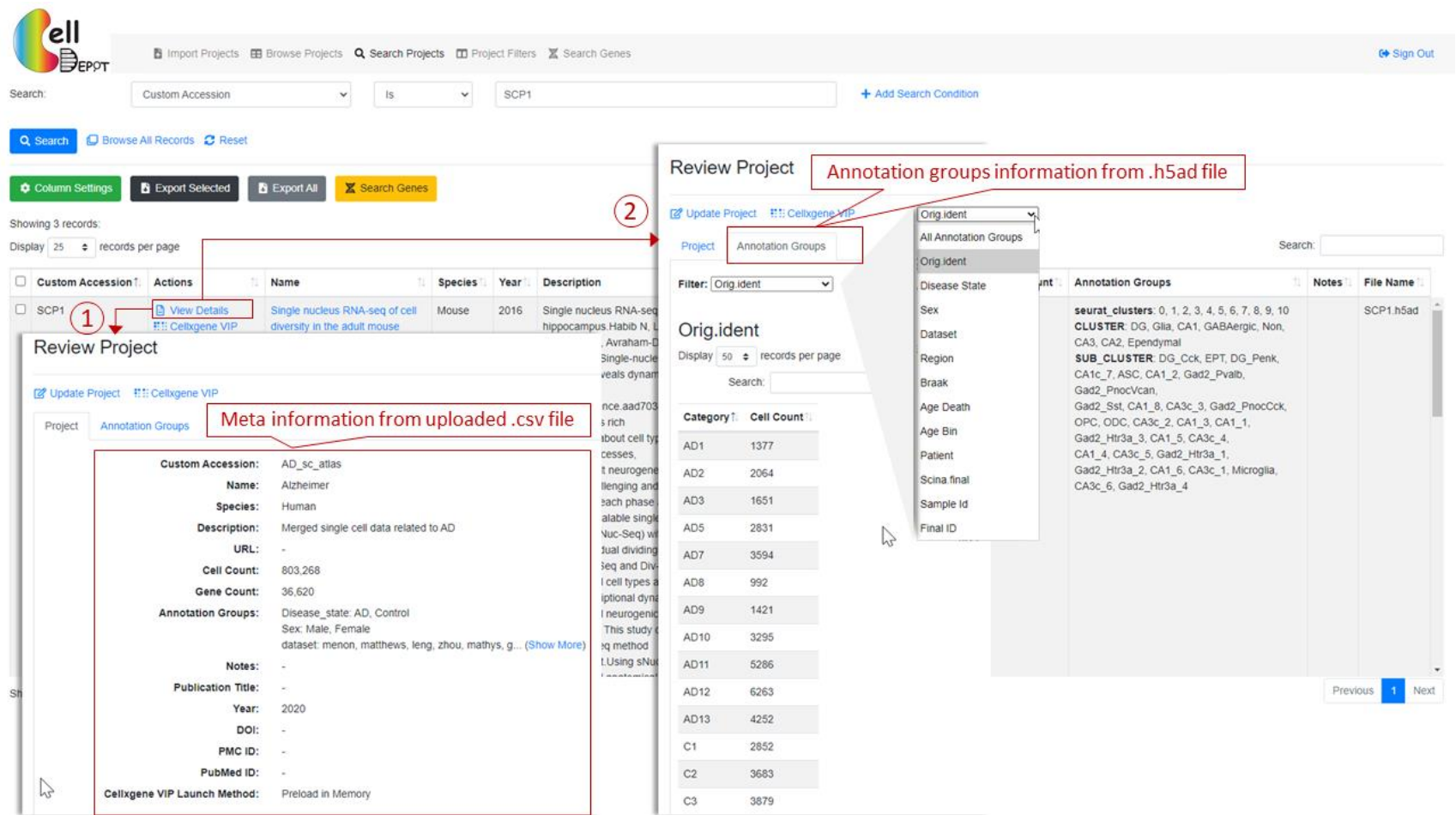

Figure S9. Visualization of details of datasets.

\subsection{Update}

Project summary information can be updated on 'Browse Project' page with 'Preload in Memory' cellxgene VIP launch method via click 'Update' hyperlink.

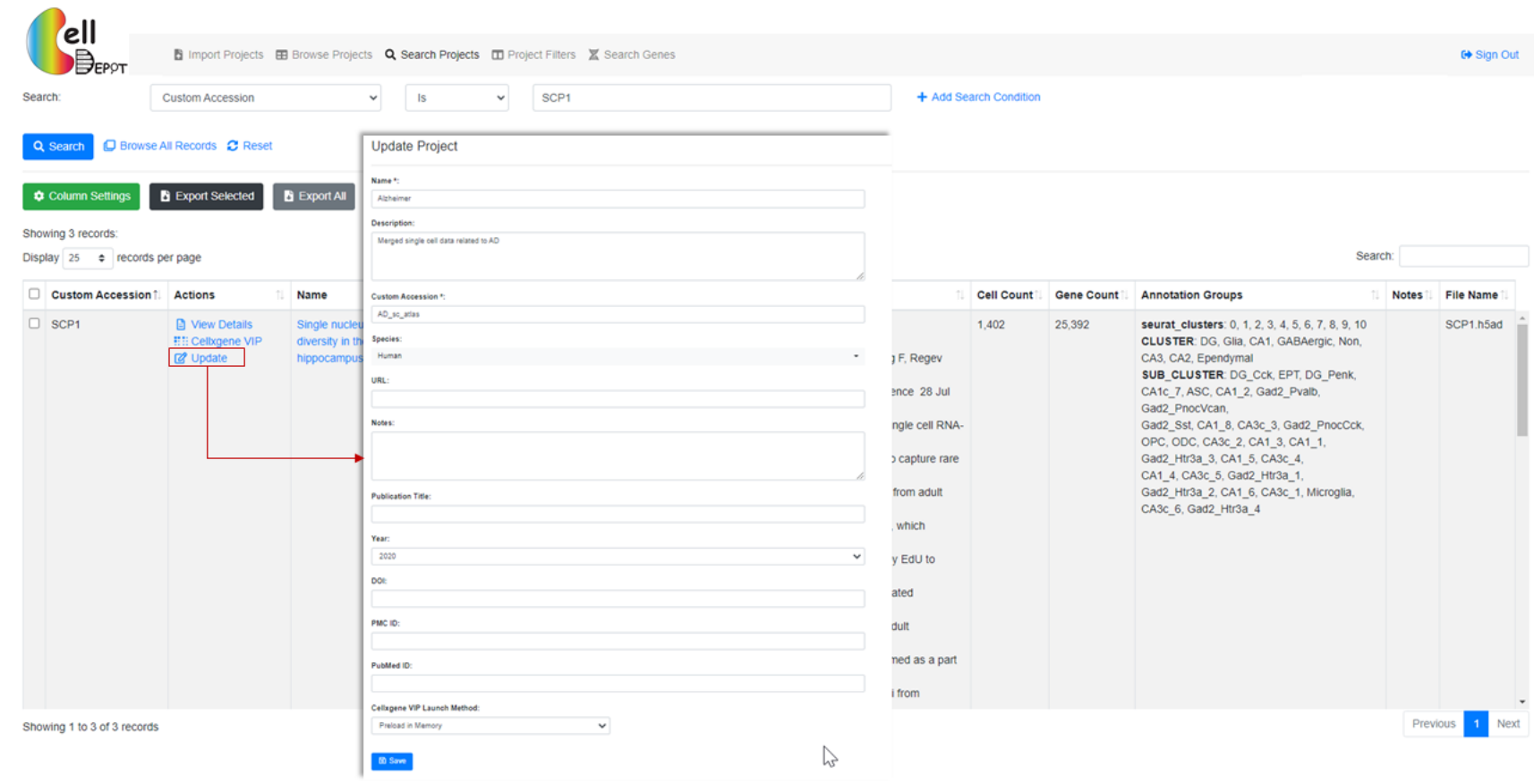

Figure S10. Update project on 'Browse Project' page. 
bioRxiv preprint doi: https://doi.org/10.1101/2021.09.30.462602; this version posted October 1, 2021. The copyright holder for this preprint (which was not certified by peer review) is the author/funder, who has granted bioRxiv a license to display the preprint in perpetuity. It is made available under aCC-BY-NC-ND 4.0 International license.

scRNA-seq dataset. Here, we embed cellxgene and cellxgene VIP in CellDepot. By clicking cellxgene VIP, please go to https://github.com/chanzuckerberg/cellxgene (cellxgene) and https://github.com/interactivereport/cellxgene VIP (cellxgene_VIP).

414

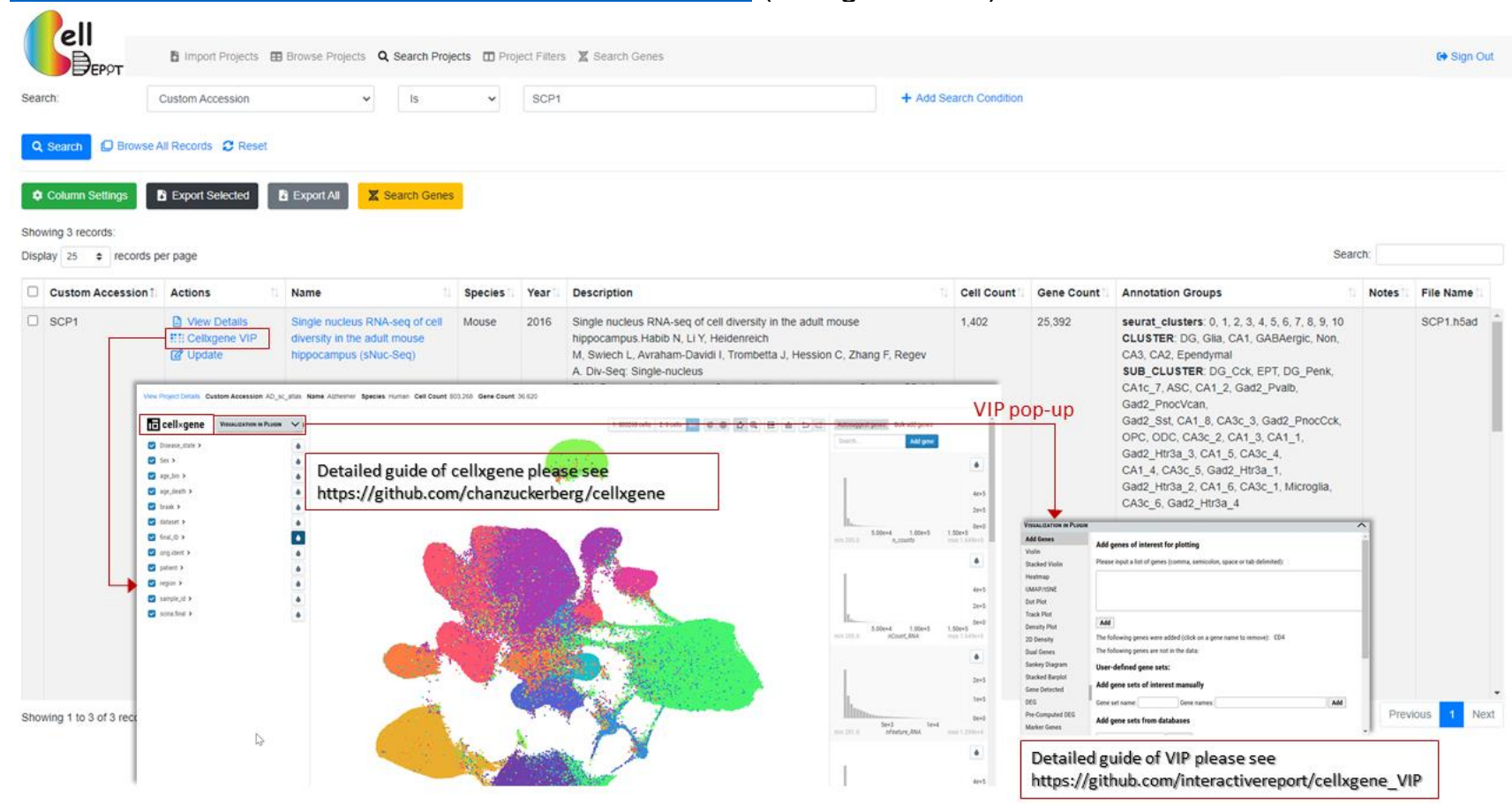

Figure S11. See visualization of selected datasets.

\section{Search Genes}

This tab allows searching on targeted genes with cell count cutoff and expression cutoff. The search outcome provides users every project contains the targeted genes. Each project displays a link to project page and a figure plot if applicable. This plot can be either violin plot or dot plot shows the gene expression level in each annotation groups. 


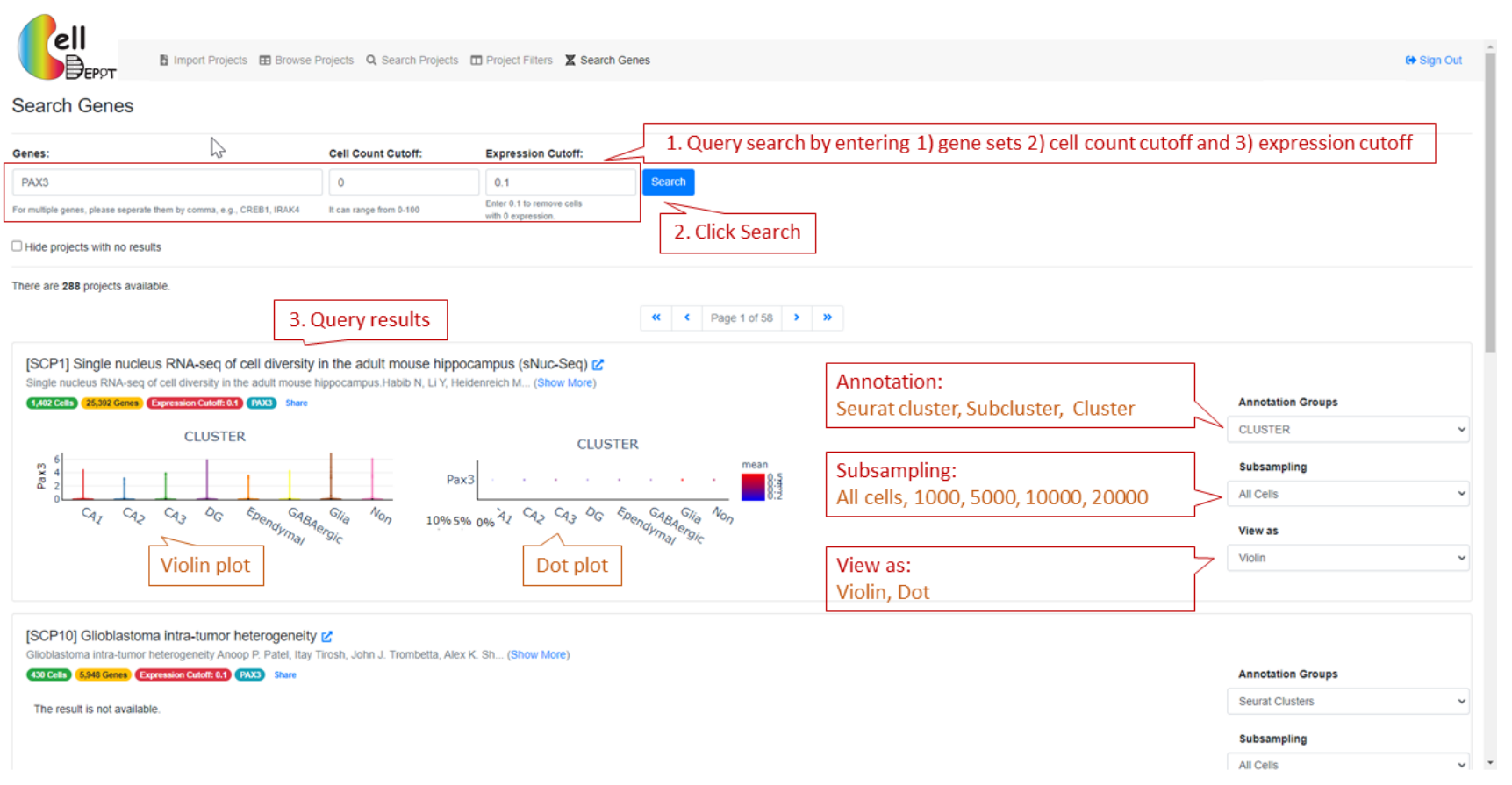

Figure S12. The layout of 'Search Genes'

\section{How to set up cron job?}

The following cron job entry is needed to convert h5ad file to CSC format on the background, @hourly <user-name>cd/var/www/html/celldepot/app/core; php ./api_toCSCh5ad.php Please make sure that the user has the permission to write in the data directory.

\section{Reference}

[1] Agarwal D, Sandor C, Volpato V, Caffrey TM, Monzon-Sandoval J, Bowden R, et al. A single-cell atlas of the human substantia nigra reveals cell-specific pathways associated with neurological disorders. Nat Commun. 2020;11:4183.

[2] Li K, Ouyang Z, Lin D, Mingueneau M, Chen W, Sexton D, et al. cellxgene VIP unleashes full power of interactive visualization, plotting and analysis of scRNA-seq data in the scale of millions of cells. 2020:2020.08.28.270652.

[3] Megill C, Martin B, Weaver C, Bell S, Prins L, Badajoz S, et al. cellxgene: a performant, scalable exploration platform for high dimensional sparse matrices. 2021:2021.04.05.438318. 